A single case of multiple arthritis will serve to illustrate the obstacles in the way of making a diagnosis.

CASE XV. CARIES OF THE ANKLE; SYMPTOMS OF SPINAL CARIES TWELVE MONTHS AFTER INVASION OF ANKLE DISEASE; MALARIAL COMPLICATIONS MASKING THE SYMPTOMS OF BONE DISEASE; SYNOVITIS OF BOTH KNEES NINE MONTHS LATER.

Harold S., aged three, came under treatment as an out-patient, December 3, 1879, with a history of lameness dating from the preceding April. The only one of the exanthemata he had had was pertussis, and this was in June, 1878. He is the third of five children, the eldest being a mute, and all are delicate. The father is reported to be rheumatic, and the grandmother to have died of apoplexy. The maternal grandmother and an aunt died of consumption. 'The mother herself is aught but healthy. The patient lives in Jersey City. The infiltration about the ankle was well marked, and the joint movements were limited to very small arcs. He was put on the iodine treatment internally and externally, and a moderate amount of rest was enjoined. February 18, 1880, for symptoms of malarial poisoning, quinine was ordered, and he was soon relieved. He attended very irregularly during the next six months, in fact he was examined April 6th, and not again until August 10th, when there were some signs of spinal caries; that is, he had pain at the epigastrium and a stiffness of the spinal column, but there was marked spinal tenderness. He had also a ravenous appetite. A blister was ordered to the spine, and on the 17th the only symptom that had disappeared was the spinal tenderness. His mother brought a specimen of his urine on the 30th. It was dark colored, alkaline in reaction, non-albuminous, but contained ahout twenty per cent. of blood. The microscopic field was full of blood corpuscles. He suffers now from a tertian type of fever, and was treated last spring for malarial fever. Next day we found on examination a moderate amount of splenic enlargement. The urine was examined two or three times, and the blood diminished in quantity as the febrile symptoms subsided. - September 8th. No pain, no stiffness, contour of spine normal.

We submitted him to a very thorough examination on the 19th of October with negative results.

December 28th. Epigastric pain has returned recently, and the boy is walking with spine stiff again. Four days ago the mother observed a little fullness of the spine between the scapulæ, and now there is a distinct angular prominence measuring one quarter of an inch in height. A brace is applied forthwith.

January 19th. Acute synovitis of left knee with considerable fluid in the joint and the leg is held in semiflexion. The circumference is only three quarters of an inch greater than that of its fellow. There is no extra heat, and very little teuderness ; motion is easily made, and the distention of the synovial sac is demonstrated when the leg is acutely flexed. He complains a little of pain in the right knee. The left is enveloped in cotton wool, and the joint is put at rest in an apparatus. 25th. Marked distention of synovial sac of right knee. 27th. Admitted to the hospital, placed in a rolling chair, knees put up in straight splints, and the effusion disappeared within a month. The functions of the joints were unimpaired, and the synovitis has not recurred. He is still under observation for the spinal caries, recovery from the knee and ankle diseases having long since been well established.

\section{THE STUDY OF ANATOMY IN THE LEIPZIG} UNIVERSITY.

BT GEORGE L. WALTON, M. D.

ONe of the advantages of German medical education is the thoroughness of the preliminary training. Two years at least are spent in the study of anatomy, human and comparative, physiology, physics, and botany, at the end of which period the student comes up for his Tentamen Physicum, familiarly called "Physicum," which is an examination in these branches. Before passing this examination his title is Studiosus Medicince; after passing it he is commonly addressed as "Herr Candidat," though the title Candidatus Medicina is not officially conferred until he has enrolled himself as a candidate for the Staats Examen, which he does two years later. The final examinations include, again, physiology and anatomy, so that these studies are not allowed to slip from the mind, as they are apt to do to a certain extent when the student feels that they are already credited to his account.

On the admirable opportunity for the study of physiology here I need not dwell. That the laboratory of Professor Ludwig offers the best possible chance for original investigation is well known, and I count the hours spent under this great master as among the most valuable as well as pleasant of my life. My present intention is, however, to detail the course of instruction in anatomy, through which the regular student must pass, as typical of the thoroughness with which the groundwork is laid in Germany in the purely scientific part of medical stuidy.

A knowledge of anutomy is required for the final examination such as no amount of book cramming will give, as may be seen from the fact that one of the tests at the last "Staats Examen" was to dissect the sphenopalatine ganglion and its branches. To this Staats Examen, which must be passed before a liceuse is granted to practice in Germany, no one is admitted who has not previously passed his Physicum; it is also expected that he has spent at least two terms in continuous dissection ; that is, every day a half day, presenting his work for inspection. It is expected that twelve parts will be dissected by each man: a head, upper and lower extremity for muscles, the same for bloodvessels, and the same for nerves. Besides this, each is expected to have dissected at least once a brain and the thoracic and abdominal viscera. Not all of the students come up to this expectation, especially in nerves, but if not it is at their own risk, as they are liable to be called on to dissect any portion of the body as a part of the final examination.

The Anatomical Institute is under the direction of Professor His, his duties being shared by Professor Braune. Both of these are names fumiliar to the medical world, the former in America principally through embryological and histological investigations, the latter more receutly through his anatomical plates. The building, which is of brick, the main division two stories high, is approximately in the form of a hollow square, two hundred and fifty feet long by two hundred deep. Its form enables the greatest possible amount of light to be secured. A broad passage way runs around three sides of the building, along the walls of which are arranged closets for the clothes of the two hundred men generally working at once in the dissecting rooms.

Un the first floor of the front of the building are 
the work rooms of Professor Braune, the working and living rooms of the prosector, Dr. Altmann, and the rooms of the assistants who prepare dissections for the lectures and assist in directing the students. In this part is also a portion of the museum, and a room for histological work. On one corner, and occupying the whole height of the building, is the large auditorium, which is furnished with two powerful electric lamps. Adjoining the auditorium is a room into which the preparations are brought before the lectures, dissections being wheeled in from the various preparing rooms on tables constructed for the purpose.

Nearly the whole rear lower floor is taken up by the dissecting rooms, one capable of accommodating one hundred and fifty men, two fifty each, and three smaller ones. They are excellently lighted by large windows, and contain boxes for the use of the students ; also instruments, bones, and plaster casts. The instruments include vises, saws, mallets, and chisels in forms to meet all possible requirements.

In the upper floor is the laboratory of Professor His, the photographing rooms formerly presided over by Honickel, whose work has a wide reputation, and the work room of the mechanic of the Institute. 'The larger museum is also in this part of the building.

The basement is occupied by the families of the mechanic, janitor, and other employees, which include a fireman, two men servants, and one who ranks higher, and whose anatomical knowledge and mechanical skill make him indispensable to the professors, for instance, in the way of making fine preparations for the class. In the basement are also the rooms in which the subjects are injected and kept. In the other parts of the building are rooms for various purposes, of which a detailed description is unnecessary.

The anatomical lectures occupy about three hours a day in winter and two in summer, the different branches being divided between the two professors. In a general way the winter term is spent more on macroscopical anatomy, and the summer term on embryology and histology. It is superfluous to mention that the lectures are amply illustrated with preparations, fresh and preserved, models, etc. Professor His is a wonderful draughtsman, and his pictures on the blackboard, in colored chalks, if accurately copied, would furnish an elegant set of plates for an anatomical work.

Another means of illustration used in the lectures is the new projecting apparatus from Basel, by which photographs of microscopical sections are thrown on a large screen.

There is also abundant opportunity for the study of normal histology, both on preparations previously made, and by the making of new ones, there being not only courses in this branch in the Anatomical Institute, but in the histological department of the Physiological Institute under Dr. Gaule. In these courses every possible facility is furnished for the student to attain proficiency in histological technique in all its branches.

Embryology is not neglected, and opportunity is offered by lecture and demonstration to beeome thoroughly familiar with this subject, which is the special province of Professor His.

The feature of the Institute which is the most striking to an American is the amount of time spent in dissecting, and the facilities for the work. Material is abundant, the principal source of supply being the criminals and suicides. The subjects for muscle prep- aration are injected with a mixture of carbolic acid, alcohol, glycerine, and water. Those for the dissection of blood-vessels are first injected with a weaker solution of the same, after which the arteries are filled with a mixture of wax and sulphate of mercury. The subjects for nerve preparation are laid at once in a forty-five per cent. solution of alcohol. During the process of dissection it is the duty of the attendants to place the parts for the night in tanks where they are soaked in alcohol and covered with cloths.

The larger dissecting room is used exclusively for the preparation of muscles and articulations, and is under the charge of Professor Braune, who, with two assistants, spends the morning examining the dissections and giving aid. The students work almost exclusively in the morning, but the rooms are open from early morning till six at night. The subjects having been prepared as described, and being kept well covered and moistened by the servants while on the tables, last indefinitely, and the time spent on a part ranges from six weeks to two months.

No one is allowed to begin on blood-vessels or nerves who has not completed the muscles. With regard to the technique of muscle dissection here, one notices that the skin is first separated from the panniculus adiposus instead of the muscle being at once dissected down upon. This is, of course, advantageous when time does not come into consideration. 'The other dissecting rooms, that is, the three generally in use, are devoted to the blood-vessels and nerves, and are under the special charge of Professor His, who, with the prosector, spends the morning in this department, the nerves coming almost exclusively under the direction of the former. That this part of the work is thoroughly done I can testify, having dissected the whole nervous system under his direction, which occupied several hours every day for five months. The most accurate work is exacted, and no advance is allowed till all preceding work approaches in every respect his ideal of what a dissection should be, and any deviation from instructions is discouraged. In this way every nerve and every anastomosis, if practicable, is reached according to a definite plan, and the nicety with which it is prepared is only limited by the skill of the student. While working in this department each man is given a hardened brain, which the professor goes over with him privately, demonstrating every part and showing the best way of exposing it.

A minor convenience worthy of note is the opportunity for the daily sharpening of instruments on the payment of about fifty cents a term, the work being done by a man employed for the express purpose.

\section{RECENT PROGRESS IN DERMATOLOGY.}

BY GEORGE H. TILDEN, M. D.

PITYRIASIS ROSEA (GIBERT); PITYRIASIS MACULATA ET CIRCINATA (BAZIN).

Frve cases of this disease, for which he proposes the name of "roseola furfuracea herpeliformis," are reported and commented upon by Dr. Behrend. As a rule, first, upon the neck, appear round or oval spots, the size of a pin's head, of a pea, or of a bean, of a rose-red color, raised slightly above the level of the 569 . 